\title{
Morphometric analysis - effect of the radiofrequency interface of electromagnetic field on the size of hatched Dermacentor reticulatus larvae
}

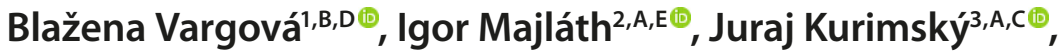 \\ Roman Cimbala ${ }^{3, A, E \oplus}$, Natália Pipová ${ }^{2, B, D \oplus}$, Jozef Živčák ${ }^{3, C \oplus}$, Piotr Tryjanowski ${ }^{4, C, E \oplus}$,

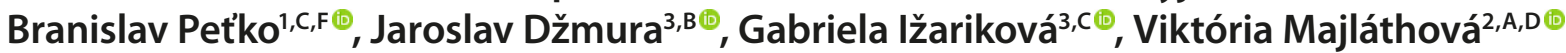 \\ ${ }^{1}$ University of Veterinary Medicine and Pharmacy in Košice, Košice, Slovak Republic \\ 2 P. J. Šafárik University in Košice, Košice, Slovak Republic \\ ${ }^{3}$ Technical University of Košice, Košice, Slovak Republic \\ ${ }^{4}$ Poznań University of Lifescience, Poznań, Poland \\ $A$ - Research concept and design, B - Collection and/or assembly of data, C - Data analysis and interpretation, \\ $D$ - Writing the article, E - Critical revision of the article, F- Final approval of the article
}

\begin{abstract}
Vargová B, Majlath I, Kurimský J, Cimbala R, Pipova N, Živčák J, Tryjanowski P, Pet'ko B, Džmura J, Ižariková G, Majláthová V. Morphometric analysis - effect of the radiofrequency interface of electromagnetic field on the size of hatched Dermacentor reticulatus larvae. Ann Agric Environ Med. 2021; 28(3): 419-425. doi: 10.26444/aaem/139289
\end{abstract}

\section{Abstract}

Introduction. Electromagnetic radiation interactions with living systems have been one of the determining factors in biological evolution. This study investigates the effect of $900 \mathrm{MHz}$ radiofrequency (RF) electromagnetics field (EMF) exposure of eggs on the development of Dermacentor reticulatus larvae.

Objective. The aim of the study was to determine whether the $900 \mathrm{MHz}$ RF-EMF has the potential to influence the size of the body of the hatched larvae of D. reticulatus ticks.

Materials and method. Eggs from 3 fully engorged females of $D$. reticulatus were included in the test procedure. Altogether, four groups of eggs were designated, including eggs from each female. A RF-EMF frequency of $900 \mathrm{MHz}$ was used. Eggs were exposed to EMF for different time periods (30,60 and 90 minutes) in a dark, electromagnetically-shielded anechoic chamber. After irradiation, eggs were allowed to hatch in a climatic chamber. Randomly selected 200 larval individuals were measured to obtain basic morphological records. Four body traits, including total body length (TBL), length of gnathosoma with scutum (GSL), total body width (TBW), and width of the basis capituli (BCW) were measured.

Results. The D. reticulatus larvae hatched from eggs exposed for 60 minutes had demonstrably larger dimensions of all measured body traits, in comparison not only to the control unexposed group, but also to the other experimental groups. Conclusions. The study shows particularly that artificial EMF used in smartphone technology impacts seriously on D. reticulatus larvae development.

\section{Key words}

electromagnetic field, development, tick, larva, body size, Dermacentor

\section{INTRODUCTION}

Electromagnetic radiation interactions with living systems have been one of the determining factors in biological evolution. Sunlight, lightning, cosmic rays, and the Earth's magnetic field are all major sources of this natural electromagnetic field (EMF). During the past century, this environmental EMF has been sharply changed with the introduction of a vast and growing spectrum of man-made EMF-producing activities and products $[1,2]$, e.g. smart phones are important tools not only for communication, but also for bank transfers, newscasts, social media and numerous other conveniences. Concerns are being raised about the emission of radio frequency (RF) EMF from these devices and their broadcasting network as this market is still

Address for correspondence: Igor Majlath, P. J. Safarik University, Kosice, Slovak Republic

E-mail: igor.majlath@upjs.sk

Received: 04.05.2021; accepted: 23.06.2021; first published:09.08.2021 growing [3]. The frequency of RF-EMF is from $100 \mathrm{MHz}$ to $6 \mathrm{GHz}$, and the main sources of RF-EMF are wireless telecommunication base stations [4].

Numerous studies have shown the sensitivity of biological systems to external artificial RF-EMF. The radiation has an impact on surrounding flora as well as on vertebrate and invertebrate organisms [5]. RF-EMF affects the insects and arachnids $[3,6]$. Insects play an important role in the balance of ecosystems. Balmori, [6] found that RF-EMF decreases the population size of insects and arachnids near the base stations. In human dwellings close to RF-EMF antennas, an absence of flies was found even in the summer period. Odemer and Odemer [7] discovered that mobile phone radiation (900 MHz RF-EMF) reduced the hatching ratio of the honeybee queen (Apis mellifera) up to $44 \%$; however, mating success was not influenced. Several authors have described that extremely low EMF $(50 \mathrm{~Hz})$ significantly increased the wing size with the opposite directional asymmetry in Drosophila subobscura and Drosophila melanogaster [8, 9]. In addition, 
other studies affirm the RF-EMF have an impact on living systems $[4,10,11,12,13,14,15]$.

Dermacentor reticulatus ticks poses a danger to humans and animals because it transmits the canine babesiosis agent (Babesia canis), several Rickettsia spp., the Omsk haemorrhagic fever virus, and Tick-borne encephalitis virus [16]. D. reticulatus is a hard tick species with a high reproduction rate. One fully engorged fertilized adult female can lay 3,000-7,000 eggs [16]. D. reticulatus female ticks provide the eggs with a secretion that prevents excessive water loss which causes the eggs to adhere in a cluster and probably protects them from fungal attack [17]. Only a few studies have shown the effect of RF-EMF on ticks. In Hyalomma asiaticum, low-power microwave modulated radiation significantly suppresses the development of both fed larvae and fed nymphs at $22^{\circ} \mathrm{C}$, whereas unfed specimens of all developmental phases were unresponsive [18]. Moreover, exposure delayed larval hatching from 3-20 days, increased the duration of activity of newly-moulted larvae by 17-24 days, and reduced the survival of unfed larvae and nymphs by 4-10 days [19]. Vargová et al., [20] observed the behavioural reaction of ticks due to $900 \mathrm{MHz}$ RF-EMF exposure in which abnormal movements of ticks were displayed as sudden jerking movements. Vargová et al., [21] used the $900 \mathrm{MHz}$ RFEMF frequency on ticks that responded by moving towards the space irradiated by these waves (used in mobile phone communication) under laboratory conditions. While RFEMF effects on behaviour in vertebrates and invertebrates have already been tested several times, no information on RF-EMF effects on body size or development of larvae of ticks exist.

In the current study, the RF-EMF frequency of $900 \mathrm{MHz}$ based radiation was used to measure the size of selected body parts of hatched larvae from eggs after exposure to RF-EMF. The objective was to determine whether the $900 \mathrm{MHz}$ RFEMF has the potential to influence the size of the body of the hatched larvae of $D$. reticulatus ticks.

\section{MATERIALS AND METHOD}

Model organism. For testing, 3 fully-engorged adult female of $D$. reticulatus were used, collected by removing them from a dog in cooperation with the University of Veterinary Medicine and Pharmacy in Kosice. Engorged ticks were kept separately in polypropylene tubes in an environmental chamber at $20^{\circ} \mathrm{C}$ and $90 \%$ relative humidity in a $16: 8$ light-dark regime. The oviposition started on day 23 after engorgement. Altogether, 3 clusters of eggs were obtained from 3 females.

Experimental setup. Egg clusters from each female were divided into 4 clutches with an average of 500 eggs each. The egg clutches were sorted into 4 groups, with eggs from all 3 females in each group (Fig. 1). The eggs were placed on Petri dishes with moistened filter paper to ensure optimal moisture and thus protect eggs from drying out. All experiments were performed in an anechoic chamber [see 20]. Petri dishes with eggs were placed into an anechoic chamber and exposed to RF-EMF. Three groups were exposed to the $900 \mathrm{MHz}$ EMF frequency with different exposure times. The first group of eggs was exposed for 30 minutes, the second group for 60 min., and the third group for $90 \mathrm{~min}$. The fourth group of

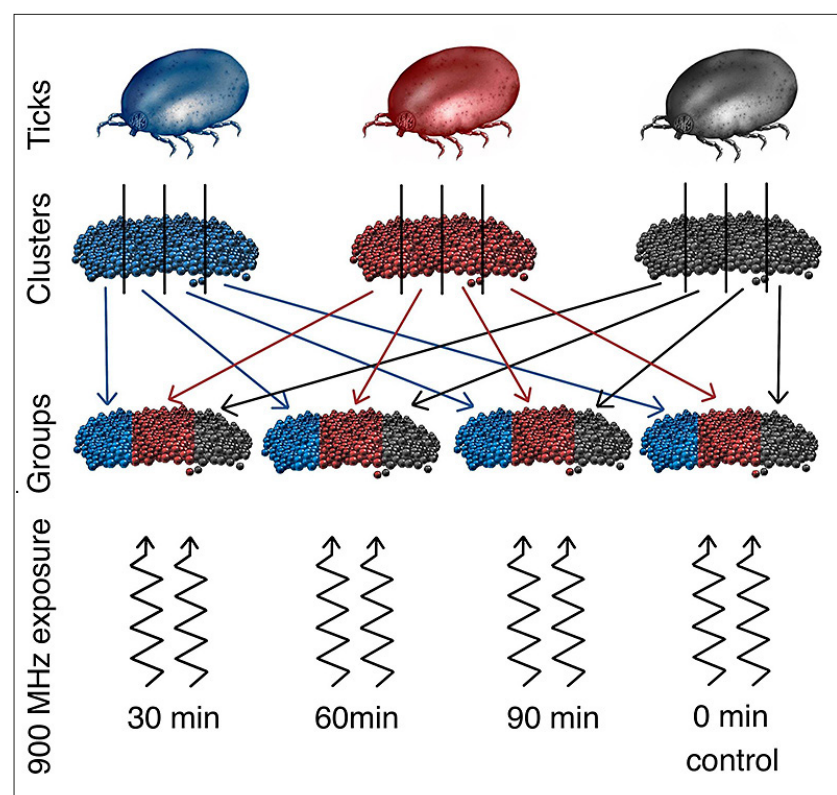

Figure 1. Schematic design of experimental groups of eggs laid by Dermacentor reticulatus ticks. Four groups of eggs were combined from clusters of eggs laid by 3 females. Three experimental groups of eggs were exposed to a $900 \mathrm{MHz}$ electromagnetic field; a group of unexposed eggs was included as the control group.

eggs was the control group that was also placed in an anechoic chamber, but without exposure of RF-EMF. At the end of the experiments, the clusters were placed in polypropylene tubes with moistened filter paper and placed in an environmental chamber at $20^{\circ} \mathrm{C}$ and $90 \%$ relative humidity in a $16: 8$ lightdark regime. Larvae began to hatch 15 days after oviposition (Fig. 2). Hatched larvae were stored in $70 \%$ ethanol.

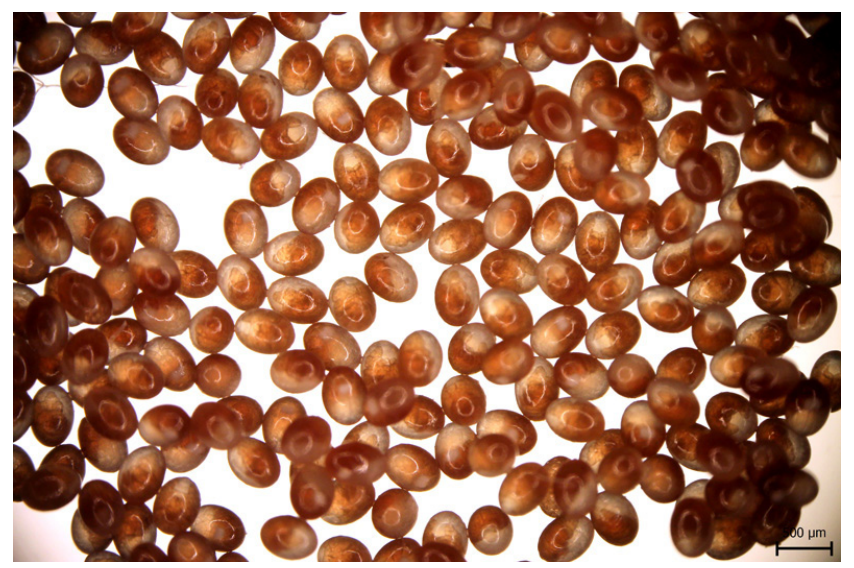

Figure 2. Eggs of Dermacentor reticulatus ticks with developed larvae inside. Photo was taken on the day of hatching. Scale bar showing $100 \mu \mathrm{m}$.

Electromagnetic conditions. By using an analogue signal generator (model N5183A, Agilent, MY) the EMF radiation of frequency $900 \mathrm{MHz}$ was generated. The object under test was irradiated by a Double-Ridged Waveguide Horn Antenna (HF907, Rohde and Schwarz, Munich, DE) with vertical polarization of the electric part of the RF field. Inspired by Salzburg Resolution on Mobile Telecommunication Base Stations [22], the power density of $1 \mathrm{mV} / \mathrm{m}^{2}$ was applied at the location of the object under the test. The setup calibration was performed,using a spectrum analyser [Spectran HF60105, Aaronia, DE]. 
Thermal conditions. The temperature of the egg groups during the experiment was stable, between $15.5-16.5^{\circ} \mathrm{C}$, and monitored by an infrared camera (FLIR T335, Flir Systems $\mathrm{AB}$, Sweden). The room temperature and humidity were monitored by a Klimalogg Base multimeter. The temperature in the anechoic chamber was $20^{\circ} \mathrm{C}$, humidity $-45 \%$.

Morphometric analysis. Fifty larvae were collected from each experimental group. A digital photo of the individual larva was taken from ventral side under a microscope using the Optic Vision Lite 2.1 optical system. A total of 4 body dimensions were measured with $0.01 \mathrm{~mm}$ accuracy. The total body length (TBL), length of gnathosoma with sclerotized dorsal plate (scutum) (GSL), total body width (TBW), and width of the basis capituli (basal portion of the capitulum on which the mouthparts are attached) (BCW) was measured. TBL was measured from the apical part of the hypostome to the caudal part of festoons, and GSL was measured from the apical part of the hypostome to the caudal part of scutum. Perpendicular to this measure was TBW, which was measured at the widest part of body (Fig. 3).

Statistical analysis. A descriptive statistics table was constructed using the dataset of measures of morphometry dimensions. The consistency of the collected experimental measures and evidence of the larvae development in different time doses time was presented by means of the data distribution kernels in the violin plots. To discover whether the irradiation in different time groups were significantly different or similar, the Tukey's test was used. To visualize the high dimensional morphometry of larvae development, 2 dimensionality reduction techniques were used: the principal component analysis (PCA) and t-distributed stochastic neighbour embedding ( $t$-SNE) space. The significance of the irradiation is interpreted in the form of the clusters in reduced data-space.

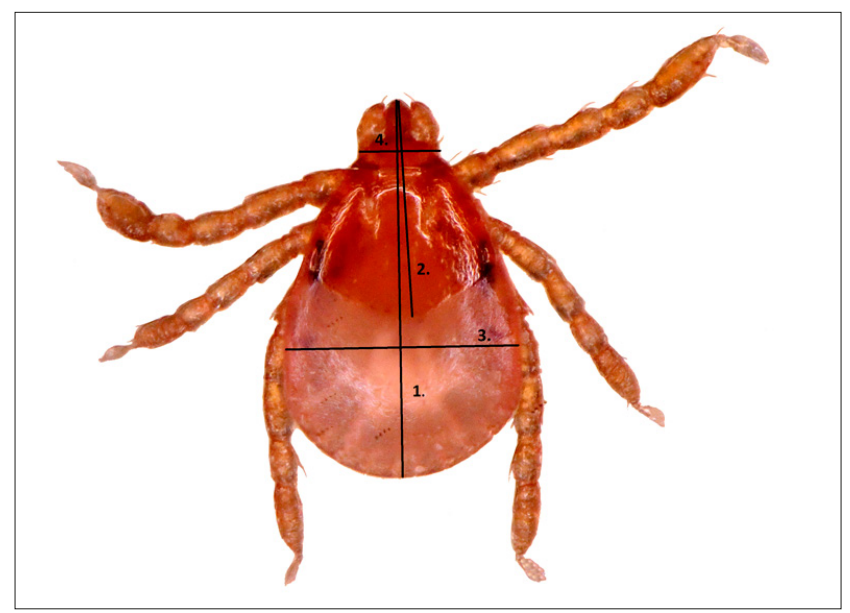

Figure 3. Larva of Dermacentor reticulatus, $x 500$ magnification. Body trait dimensions measured in this study are indicated by black lines as follows: 1) total body length (TBL); 2) length of gnathosoma with scutum (GSL); 3 ) total body width (TBW); 4) the width of basis capituli (BCW). Trait No. 2 is diverted in the picture for illustration, otherwise it overlaps with trait No. 1.

\section{RESULTS}

The experimental sample consisted of the morphometry dimensions measured on 200 hatched larvae originating from 4 groups. Altogether, 800 dimensions were measured, 4 parameters on each individual tick. Besides the control set $(\mathrm{N}=50)$, they were irradiated for $30(\mathrm{~N}=50), 60(\mathrm{~N}=50)$ and $90(\mathrm{~N}=50)$ minutes, respectively. Measurements of the irradiated egg clutches were compared with the control set measures. Descriptive statistics of larvae development morphometry measurements are shown in Table 1, Figure 4, and Graph 1.

The most significant differences between the measured parameters occurred in the $900 \mathrm{MHz}$ group exposed for 60 min. The ticks $D$. reticulatus exposed for 60 minutes had demonstrably larger body dimensions of all measured parts,

Table 1. Descriptive statistics of larvae development morphometry measures. TBL - total body length, GSL - length of gnathosoma with scutum, TBW - total body width, BCW - width of basis capituli

\begin{tabular}{|c|c|c|c|c|c|c|c|c|c|}
\hline $\begin{array}{l}\text { Body } \\
\text { dimension }\end{array}$ & $\begin{array}{l}\text { Dose time } \\
\text { (s) }\end{array}$ & $\mathrm{N}$ & Mean (mm) & $\begin{array}{l}\text { Standard Deviation } \\
(\mathrm{mm})\end{array}$ & $\begin{array}{l}\text { Lower } 95 \% \mathrm{Cl} \text { of Mean } \\
(\mathrm{mm})\end{array}$ & $\begin{array}{l}\text { Upper } 95 \% \mathrm{Cl} \text { of Mean } \\
(\mathrm{mm})\end{array}$ & $\begin{array}{l}\text { Minimum } \\
(\mathrm{mm})\end{array}$ & $\begin{array}{l}\text { Median } \\
(\mathrm{mm})\end{array}$ & $\begin{array}{l}\text { Maximum } \\
\quad(\mathrm{mm})\end{array}$ \\
\hline TBL & 0 & 50 & 0.693 & 0.012 & 0.690 & 0.697 & 0.669 & 0.696 & 0.724 \\
\hline TBW & 0 & 50 & 0.367 & 0.033 & 0.358 & 0.376 & 0.158 & 0.373 & 0.398 \\
\hline BCW & 0 & 50 & 0.153 & 0.033 & 0.144 & 0.162 & 0.128 & 0.150 & 0.375 \\
\hline GSL & 0 & 50 & 0.399 & 0.010 & 0.396 & 0.402 & 0.377 & 0.398 & 0.424 \\
\hline TBL & 30 & 50 & 0.678 & 0.012 & 0.675 & 0.682 & 0.653 & 0.678 & 0.711 \\
\hline TBW & 30 & 50 & 0.362 & 0.015 & 0.358 & 0.366 & 0.335 & 0.363 & 0.389 \\
\hline BCW & 30 & 50 & 0.139 & 0.007 & 0.137 & 0.140 & 0.126 & 0.138 & 0.162 \\
\hline GSL & 30 & 50 & 0.387 & 0.009 & 0.384 & 0.389 & 0.367 & 0.385 & 0.403 \\
\hline TBL & 60 & 50 & 0.715 & 0.014 & 0.711 & 0.719 & 0.679 & 0.715 & 0.748 \\
\hline TBW & 60 & 50 & 0.378 & 0.014 & 0.374 & 0.382 & 0.348 & 0.377 & 0.409 \\
\hline BCW & 60 & 50 & 0.145 & 0.007 & 0.143 & 0.147 & 0.132 & 0.144 & 0.163 \\
\hline TBL & 90 & 50 & 0.636 & 0.017 & 0.631 & 0.641 & 0.601 & 0.635 & 0.672 \\
\hline TBW & 90 & 50 & 0.344 & 0.016 & 0.339 & 0.348 & 0.300 & 0.343 & 0.380 \\
\hline BCW & 90 & 50 & 0.135 & 0.009 & 0.133 & 0.138 & 0.115 & 0.136 & 0.156 \\
\hline GSL & 90 & 50 & 0.363 & 0.014 & 0.359 & 0.367 & 0.333 & 0.364 & 0.397 \\
\hline
\end{tabular}




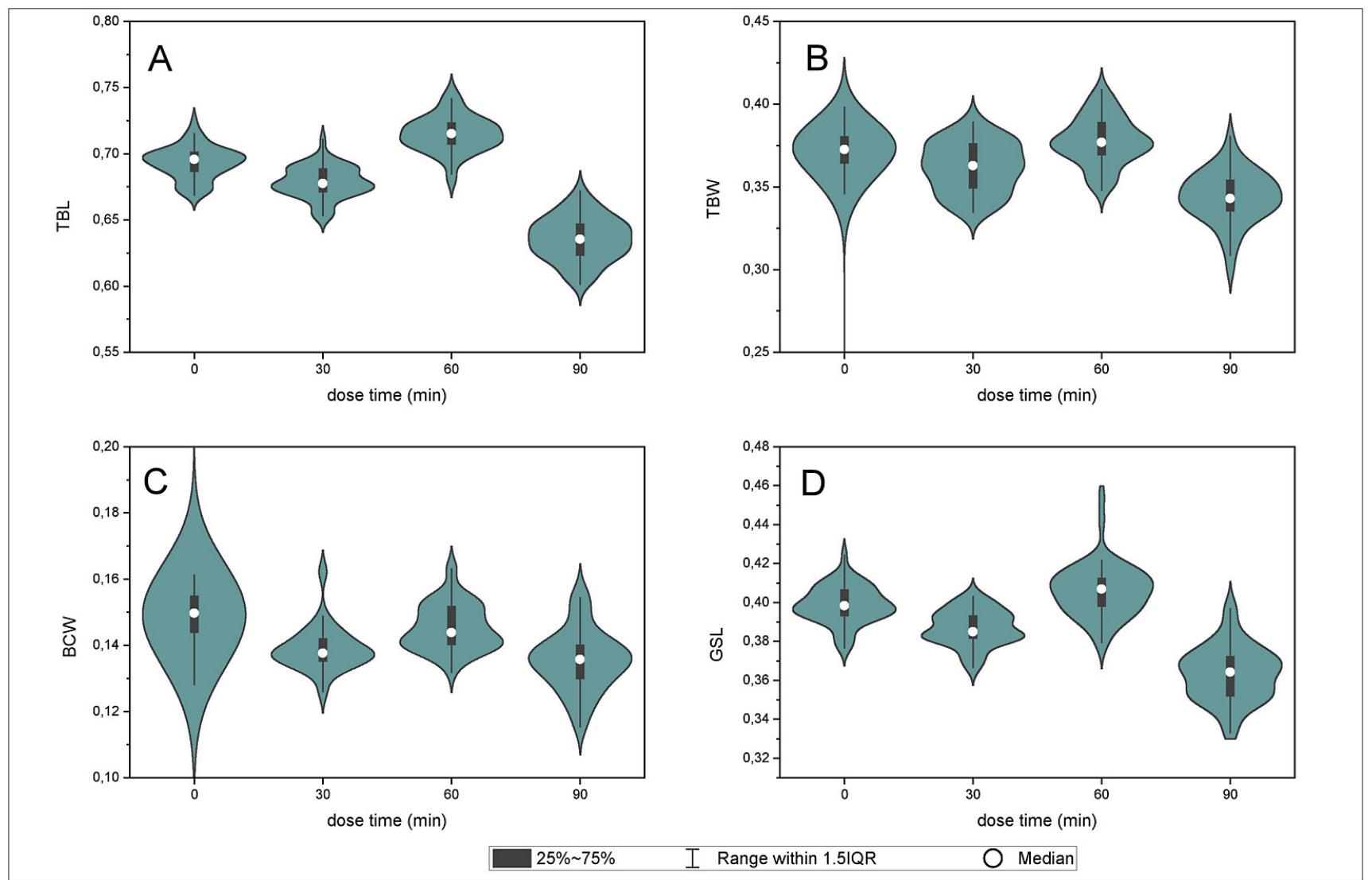

Figure 4. Quartiles and data distribution kernels describing the measured body trait dimensions of Dermacentor reticulatus larvae hatched from eggs exposed to a $900 \mathrm{MHz}$ electromagnetic field with different exposure time.

TBL - total body length; GSL - length of gnathosoma with scutum; TBW - total body width; BCW - width of basis capituli

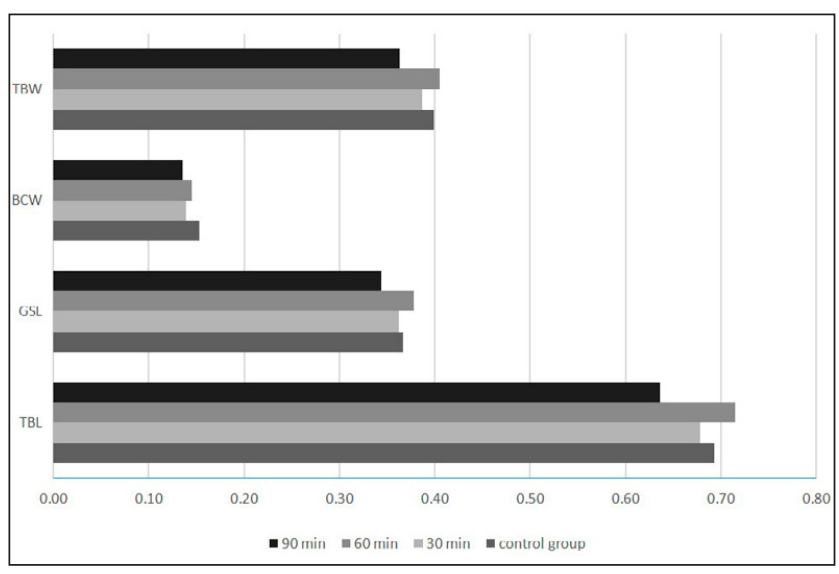

Graph 1. Comparison of mean values of measured body traits in all experimental groups.

TBL - total body length; GSL - length of gnathosoma with scutum; TBW - total body width; BCW - width of basis capituli).

not only as a control group, but also in the other groups. The greatest difference was seen in the length of the gnathosoma and scutum where the average was $0.72 \mathrm{~mm}$, compared to the larval control group, where this parameter was $0.69 \mathrm{~mm}$. Length of scutum in the 60 min exposed group, on average, was $0.01 \mathrm{~mm}$ larger than in the control group. Equally, larger dimensions were recorded in the width of the scutum $0.02 \mathrm{~mm}$. There was no significant difference in the width of the basis capituli, No deformations or other anomalies were observed.
The significance of the irradiation impact on the larvae development was validated by the ANOVA Tukey Test at significance level 0.05 . The probability and significance are shown in in Table 2.

To show the different variability of measured parameters, principal component analysis (PCA) was conducted. Four principal components (PC1-C4) cover $100 \%$ variability of measured values. The proportion of variance of the components, their eigenvalues and feature contributions are shown in Table 3, and informative projection of the most important components PC1 vs PC2 is shown in Figure 5. Colours are used to show the contributions of irradiation lasting to the component values. There are 4 main areas on the graph that belong to the dose time, which indicates that there is clear evidence of irradiation of the egg clutches development.

\section{DISCUSSION}

D. reticulatus is a hard tick with unique biology and ecology; it is extremely tolerant to a wide spectrum of unfavourable conditions and has a high adaptivity, which led to its spreading into new areas. D. reticulatus ticks play an important role in the transmission of pathogens that can potentially be transmitted by several viruses, bacteria and protists. D. reticulatus females lay up to 7,200 eggs and the adults are very resistant to the external environment [16]. Although great progress has been made in knowledge of the eco-epidemiology of this species, several gaps still need to 
Table 2. Test of significance of irradiation impact on larvae development

\begin{tabular}{|c|c|c|c|c|c|c|c|c|c|}
\hline Dependent variable & Factor levels & MeanDiff & SEM & q Value & Prob & Alpha & Sig & $\mathrm{LCL}$ & UCL \\
\hline \multirow[t]{5}{*}{ TBL } & 30_0 & -0.01502 & 0.00274 & 7.73821 & $\approx 0$ & 0.05 & 1 & -0.02213 & -0.00791 \\
\hline & 60_0 & 0.02181 & 0.00274 & 11.23431 & 0 & 0.05 & 1 & 0.01469 & 0.02892 \\
\hline & 60_30 & 0.03683 & 0.00274 & 18.97252 & $\approx 0$ & 0.05 & 1 & 0.02971 & 0.04394 \\
\hline & 90_0 & -0.05747 & 0.00274 & 29.61084 & $\approx 0$ & 0.05 & 1 & -0.06459 & -0.05036 \\
\hline & 90_30 & -0.04245 & 0.00274 & 21.87263 & 0 & 0.05 & 1 & -0.04957 & -0.03534 \\
\hline Dependent variable & Factor levels & MeanDiff & SEM & q Value & Prob & Alpha & Sig & $\mathrm{LCL}$ & UCL \\
\hline \multirow[t]{5}{*}{ TBW } & 30_0 & -0.00519 & 0.00419 & 1.74952 & 0.60405 & 0.05 & 0 & -0.01605 & 0.00568 \\
\hline & 60_0 & 0.01072 & 0.00419 & 3.61603 & 0.0546 & 0.05 & 0 & $-1.44 \mathrm{E}-04$ & 0.02158 \\
\hline & 60_30 & 0.0159 & 0.00419 & 5.36555 & 0.00112 & 0.05 & 1 & 0.00504 & 0.02676 \\
\hline & 90_30 & -0.018 & 0.00419 & 6.07229 & $\approx 0$ & 0.05 & 1 & -0.02886 & -0.00714 \\
\hline & $90 \_60$ & -0.0339 & 0.00419 & 11.43784 & 0 & 0.05 & 1 & -0.04476 & -0.02304 \\
\hline Dependent variable & Factor levels & MeanDiff & SEM & q Value & Prob & Alpha & Sig & $\mathrm{LCL}$ & UCL \\
\hline \multirow[t]{6}{*}{ BCW } & 30_0 & -0.01413 & 0.00356 & 5.61807 & $» 0$ & 0.05 & 1 & -0.02335 & -0.00491 \\
\hline & 60_0 & -0.00773 & 0.00356 & 3.0718 & 0.13469 & 0.05 & 0 & -0.01694 & 0.00149 \\
\hline & 60_30 & 0.0064 & 0.00356 & 2.54627 & 0.27621 & 0.05 & 0 & -0.00281 & 0.01562 \\
\hline & 90_0 & -0.01773 & 0.00356 & 7.0515 & $» 0$ & 0.05 & 1 & -0.02695 & -0.00852 \\
\hline & 90_30 & -0.00361 & 0.00356 & 1.43343 & 0.74168 & 0.05 & 0 & -0.01282 & 0.00561 \\
\hline & $90 \_60$ & -0.01001 & 0.00356 & 3.9797 & 0.02742 & 0.05 & 1 & -0.01923 & $-7.93 E-04$ \\
\hline Dependent variable & Factor levels & MeanDiff & SEM & q Value & Prob & Alpha & Sig & $\mathrm{LCL}$ & $\mathrm{UCL}$ \\
\hline & $60 \_0$ & 0.00733 & 0.00236 & 4.39142 & 0.01163 & 0.05 & 1 & 0.00121 & 0.01345 \\
\hline & 60_30 & 0.01923 & 0.00236 & 11.52127 & 0 & 0.05 & 1 & 0.01312 & 0.02535 \\
\hline & 90_0 & -0.0354 & 0.00236 & 21.20412 & 0 & 0.05 & 1 & -0.04152 & -0.02928 \\
\hline & 90_30 & -0.0235 & 0.00236 & 14.07427 & 0 & 0.05 & 1 & -0.02961 & -0.01738 \\
\hline & $90 \_60$ & -0.04273 & 0.00236 & 25.59554 & 0 & 0.05 & 1 & -0.04885 & -0.03661 \\
\hline
\end{tabular}

MeanDiff - mean difference, SEM - standard error of the mean, Prob - probability, Alpha - significance level, Sig - significance, LCL - lower bound of confidence, UCL - upper bound of confidence, Sig equals 1 indicates that difference of means is significant at level 0.05 , Sig equals 0 indicates that difference of means is not significant at level 0.05 . TBL - total body length, GSL - length of gnathosoma with scutum, TBW - total body width, BCW - width of basis capituli

Table 3. Principal component analysis of experimental data. TBL - total body length, GSL - length of gnathosoma with scutum, TBW - total body width, BCW-width of basis capituli

\begin{tabular}{lcccccc}
\hline $\begin{array}{l}\text { Principal } \\
\text { Component } \\
\text { Number }\end{array}$ & $\begin{array}{c}\text { Proportion } \\
\text { of } \\
\text { variance }\end{array}$ & $\begin{array}{l}\text { Eigen- } \\
\text { values }\end{array}$ & TBL & TBW & BCW & GSL \\
\hline PC1 & $57.35 \%$ & 2.29405 & 0.62309 & 0.45064 & 0.14546 & 0.62251 \\
\hline PC2 & $32.36 \%$ & 1.29448 & 0.10057 & -0.55556 & 0.81796 & 0.11038 \\
\hline PC3 & $6.89 \%$ & 0.27565 & -0.32259 & 0.69877 & 0.5565 & -0.31299 \\
\hline PC4 & $3.40 \%$ & 0.13582 & 0.7054 & 0.00070 & 0.00939 & -0.70875 \\
\hline
\end{tabular}

be filled. Several important biotic and abiotic factors have already been identified as affecting the biology of this tick species. In several publications, an electro-magnetic field was found to affect the behavioural features of Dermacentor ticks, and also showed different affinity to the EMF frequency [21]. The occurrence of man-made electromagnetic fields is constantly increasing in the environment, not only in urban but also in the natural habitat. In recent years, the public has been widely and increasingly using mobile phones with 900

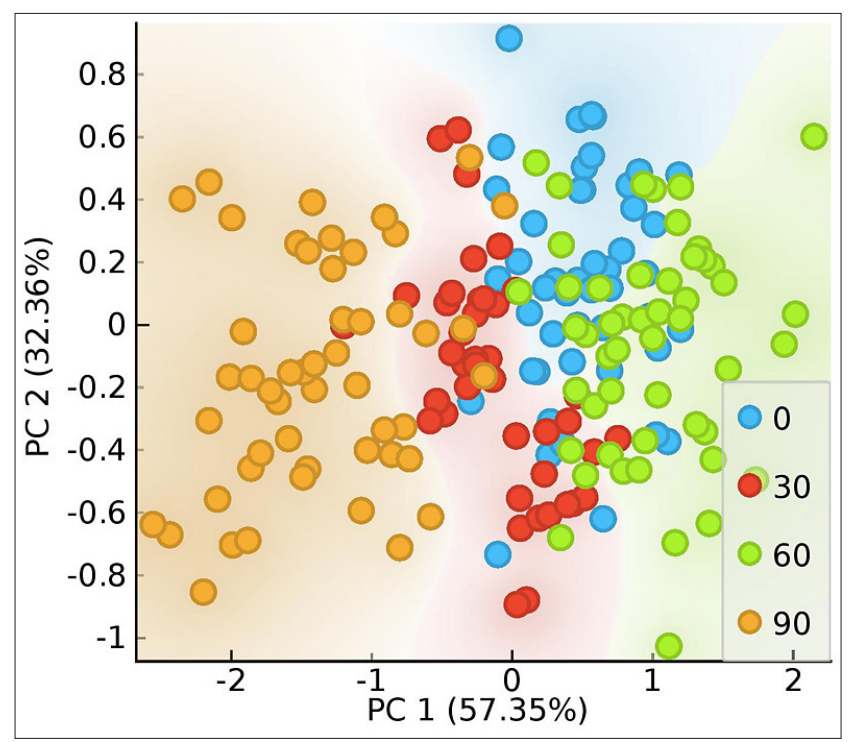

Figure 5. Projection of principal component analysis. PC1 vs PC2 components are shown 
$\mathrm{MHz}$ frequency [6]. The effect of this frequency on biological objects is still insufficiently investigated. The current study aimed investigate the of effect of the $900 \mathrm{MHz}$ frequency on the development of larvae in eggs, and investigation the morphological differences in the hatched larvae. This study is the first scientific report on the effect of RF- EMF on the body size of $D$. reticulatus larvae. The studied $900 \mathrm{MHz}$ RF-EMF frequency is the one typically emitted by telecommunication antennas, mobile phones, and other transmitters, which are very abundant in the environment.

Morphometric analysis data clearly indicated that radiation has a significant impact on the evaluated body traits of $D$. reticulatus larvae. Surprisingly, the morphometry results obtained from EMF exposed larvae were not consistent. It cannot concluded whether the effect of EMF on body trait enhances or limits the growth of the larvae, compared to the non-exposed control. In the eggs exposed for 30 and 90 minutes exposure, a limitation in growth was observed in all parameters, and 60 minutes exposure had a significant growth-enhancing effect in all observed parameters. The impact of EMF was also studied by Korotkov et al. [18] who showed that the hatching and metamorphosis of the Hyalomma asiaticum tick is affected by low-power (20 microW/ $\mathrm{cm}^{2}$ ) microwave-modulated radiation.

Morphometric analysis without the influence of RFEMF was performed on $D$. reticulatus ticks' larvae. The size and width of larval tarsus were compared between the tick populations of Poland and Slovakia, with significant differences found between populations [23]. Studies dealing with larval development were focused mainly of the presence of body malformations. Environmental stressors, such as high temperature, humidity, use of chemicals in the environment, and host resistance to tick infestation, are among the main causes of morphological abnormalities in ticks $[23,24,25]$. The effect of high relative humidity on larval development showed harmful influence on the embryonic development of Hyalomma marginatum [26]. Experiments by Buczek et al. [23] confirmed that colchicine, a cytotoxic alkaloid of plant origin, caused the death of eggs and embryos, disruption of larval hatching, and the development of morphological anomalies in larvae. Morphological abnormalities (heteromorphosis of leg segments, oligomely, heterosymely, atrophy, altered shape, etc.) were found in $0.2 \%$ of the larvae. Developmental abnormalities were also observed in the environment with high anthropogenic pressure, without identification of exact cause of the malformations [27,28]. Morphological anomalies can occur in any developmental stage (i.e. larva, nymph or adult) in natural populations of ixodid ticks. Malformations were more often expressed in the Ixodes persulcatus than Dermacentor and Haemaphysalis ticks studied in the Altai Republic in Russia. When considering the presence of tickbone encephalitis virus in ticks, the percentage of infected abnormal ticks was lower than of Ixodes without exoskeleton anomalies [29].

Mirabolghasemi and Azarnia described the biological effect of EMF on the developmental stages of Drosophila melanogaster eggs, and the first, second and third instar of larvae. Larvae exposed to EMF showed a higher incidence of abnormalities and was influenced by the duration of exposure. Their findings indicate a significant increase in the number of abnormal adult flies, whereas no significant increase was observed in the group arising from eggs exposed to EMF [9].
Panagopoulos et al. [30] described the reproductive capacity of Drosophila melanogaster, and discovered that the RF-EMF $900 \mathrm{MHz}$ frequency decreased reproduction of the insect by $50 \%-60 \%$.

Current understanding of the life-cycle traits and ecological aspects of $D$. reticulatus is rather limited compared to the well-studied Ixodes spp. ticks. This is mainly due to the lack of information concerning the developmental stages which are largely hidden, and it is almost impossible to collect them in the field. Morphological studies of the body traits of larvae are limited to laboratory-reared ticks.

\section{CONCLUSION}

The presented study reports for the first time the morphological changes in $D$. reticulatus larvae hatched from EMF exposed eggs. Further studies with longer exposures, other frequencies or intensities of EMF, repeated exposures or exposure of other developmental stages also focusing on developmental malformations, would have a high scientific value.

\section{Acknowledgement}

This work was financially supported by the Slovak Research and Development Agency project number APVV-17-0372 and VEGA 2/0113/18. We thank Barbora Majláthová for graphical design of figure 1 and Iveta Oreničová for help in the laboratory.

\section{REFERENCES}

1. Adey WR. Biological effects of electromagnetic fields. J Cell Biochem. 1993;51(4):410-416. doi:10.1002/jcb.2400510405

2. Calvente I, Fernandez MF, Villalba J, Olea N, Nuñez MI. Exposure to electromagnetic fields (non-ionizing radiation) and its relationship with childhood leukemia: A systematic review. Sci Total Environ. 2010;408(16):3062-3069. doi:10.1016/j.scitotenv.2010.03.039

3. Balmori A. Anthropogenic radiofrequency electromagnetic fields as an emerging threat to wildlife orientation. Sci Total Environ. 2015;518519:58-60. doi:10.1016/j.scitotenv.2015.02.077

4. Bhatt CR, Thielens A, Billah B, et al. Assessment of personal exposure from radiofrequency-electromagnetic fields in Australia and Belgium using on-body calibrated exposimeters. Environ Res. 2016;151:547-563. doi:10.1016/j.envres.2016.08.022

5. Cucurachi S, Tamis WLM, Vijver MG, Peijnenburg WJGM, Bolte JFB, de Snoo GR. A review of the ecological effects of radiofrequency electromagnetic fields (RF-EMF). Environ Int. 2013;51:116-140. doi:10.1016/j.envint.2012.10.009

6. Balmori A. Electromagnetic pollution from phone masts. Effects on wildlife. Pathophysiology. 2009;16(2):191-199. doi:10.1016/j. pathophys.2009.01.007

7. Odemer R, Odemer F. Effects of radiofrequency electromagnetic radiation (RF-EMF) on honey bee queen development and mating success. Sci Total Environ. 2019;661:553-562. doi:10.1016/j. scitotenv.2019.01.154

8. Patenkovic A, Savic T, Kenig B, Kurbalija-Novicic Z, Andjelkovic M. The impact of extremely low frequency electromagnetic field $(50 \mathrm{~Hz}, 0.25$ $\mathrm{mT}$ ) on fitness components and wing traits of Drosophila subobscura. Genetika. 2015;47(3):967-982. doi:10.2298/GENSR1503967P

9. Mirabolghasemi G, Azarnia M. Developmental changes in Drosophila melanogaster following exposure to alternating electromagnetic fields. Bioelectromagnetics. 2002;23(6):416-420. doi:10.1002/bem.10042

10. Beuthner U. On the sterile male release technique: sterilization by $\gamma$-radiation (60Co) in Amblyomma variegatum (Fabricius, 1794), Hyalomma anatolicum excavatum (Koch, 1844), and Rhipicephalus appendiculatus (Neumann, 1901). Published online 1975. Accessed April 25, 2016. http://inis.iaea.org/Search/search.aspx?orig_q=RN:8310484 
11. Fernie KJ, Bird DM. Effects of Electromagnetic Fields on Body Mass and Food-Intake of American Kestrels. The Condor. 1999;101(3):616-621. doi:10.2307/1370191

12. Gould JL. Magnetic Field Sensitivity in Animals. Annu Rev Physiol. 1984;46(1):585-598. doi:10.1146/annurev.ph.46.030184.003101

13. Panagopoulos DJ, Chavdoula ED, Karabarbounis A, Margaritis LH. Comparison of Bioactivity Between GSM $900 \mathrm{MHz}$ and DCS $1800 \mathrm{MHz}$ Mobile Telephony Radiation. Electromagn Biol Med. 2007;26(1):33-44. doi:10.1080/15368370701205644

14. Vácha $\mathrm{M}$, Půžová $\mathrm{T}$, Kvíćalová $\mathrm{M}$. Radio frequency magnetic fields disrupt magnetoreception in American cockroach. J Exp Biol. 2009;212(21):3473-3477. doi:10.1242/jeb.028670

15. Vácha M, Kvíčalová M, Půžová T. American cockroaches prefer four cardinal geomagnetic positions at rest. Behaviour. 2010;147(4):425-440. doi:10.1163/000579509X12580965484148

16. Földvári G, Široký P, Szekeres S, Majoros G, Sprong H. Dermacentor reticulatus: a vector on the rise. Parasit Vectors. 2016;9:314. doi:10.1186/ s13071-016-1599-x

17. Schöl H, Sieberz J, Göbel E, Gothe R. Morphology and structural organization of Genés organ in Dermacentor reticulatus (Acari: Ixodidae). Exp Appl Acarol. 2001;25(4):327-352. doi:10.1023/A:1017963531560

18. Korotkov I, La B, Ms B, VIu P. [The impact of electromagnetic radiation at microwave frequency $(9.8 \mathrm{HhZ})$ on the embryonic and postembryonic development of the tick Hyalomma asiaticum (Acarina, Ixodidae)]. Med Parazitol (Mosk). 1999;(1):38-42.

19. Korotkov IS, Burenkov MS, Burenkova LA, Pichugin VI, Chunikhin SP, Engovatov VV. [The reaction of the tick Hyalomma asiaticum (Acarina, Ixodidae) to 1- to 4-GHz microwaves]. Med Parazitol (Mosk). 1996;(4):28-31.

20. Vargová B, Kurimský J, Cimbala R, et al. Ticks and radio-frequency signals: behavioural response of ticks (Dermacentor reticulatus) in a $900 \mathrm{MHz}$ electromagnetic field. Syst Appl Acarol. 2017;22(5):683-693. doi:10.11158/saa.22.5.7

21. Vargová B, Majláth I, Kurimský J, et al. Electromagnetic radiation and behavioural response of ticks: an experimental test. Exp Appl Acarol. 2018;75(1):85-95. doi:10.1007/s10493-018-0253-z.
22. Salzburg Resolution on Mobile Telecommunication Base Stations, 2000 International Conference on Cell Tower Siting Linking Science \& Public Health“, Salzburg, Austria, June 7-8, 2000)

23. Buczek A, Buczek L, Kuśmierz A, Olszewski K, Stanko M. [Morphometric features of tarsus in Dermacentor reticulatus (Fabricius, 1794) (Acari: Ixodida: Ixodidae) larvae from Polish and Slovakian populations]. Wiad Parazytol. 2001;47(3):291-295.

24. Keskin A, Simsek E, Bursali A, Keskin A. Morphological abnormalities in ticks (Acari: Ixodidae) feeding on humans in Central Black Sea region, Turkey. Zoomorphology. 2016;135(2):167-172. doi:10.1007/ s00435-016-0306-y

25. Shuaib YA, Isaa MH, Ezz-Eldin MI-E, Abdalla MA, Bakhiet AO, Chitimia-Dobler L. Morphological abnormalities in ticks (Acari: Ixodidae) collected from domestic animal species in Sudan. Exp Appl Acarol. 2020;82(1):161-169. doi:10.1007/s10493-020-00534-x

26. Buczek A. Experimental Teratogeny in the Tick Hyalomma marginatum marginatum (Acari: Ixodida: Ixodidae): Effect of High Humidity on Embryonic Development. J Med Entomol. 2000;37(6):807-814. doi:10.1603/0022-2585-37.6.807

27. Alekseev AN, Jensen PM, Dubinina HV, Smirnova LA, Makrouchina NA, Zharkov SD. Peculiarities of behaviour of taiga (Ixodes persulcatus) and sheep (Ixodes ricinus) ticks (Acarina: Ixodidae) determined by different methods. Folia Parasitol (Praha). 2000;47(2):147-153. doi:10.14411/fp.2000.029

28. Zharkov SD, Dubinina HV, Alekseev AN, Jensen PM. Anthropogenic pressure and changes in Ixodes tick populations in the Baltic region of Russia and Denmark. Acarina. 2000;8(2):137-141.

29. Sshuchinova LD. Occurrence of ixodic ticks with exoskeleton anomalies and their infection with tick-borne encephalitis in Altai Republic. Ross Parazitol Zhurnal. 2014;(No.2):18-21.

30. Panagopoulos DDJ, Karabarbounis A, Margaritis LH. Effect of GSM 900-MHz Mobile Phone Radiation on the Reproductive Capacity of Drosophila melanogaster. Electromagn Biol Med. 2004;23(1):29-43. doi:10.1081/JBC-120039350 